\title{
Morpho-functional architecture of the Golgi complex of neuroendocrine cells
}

\section{Emma Martínez-Alonso ${ }^{1}$, Mónica Tomás ${ }^{2}$ and José A. Martínez-Menárguez ${ }^{1 *}$}

1 Department of Cell Biology and Histology, Medical School, University of Murcia, Murcia, Spain

2 Department of Human Anatomy and Embryology, Medical School, Valencia University, Valencia, Spain

\section{Edited by:}

Rafael Vazquez-Martinez, University of Cordoba, Spain

\section{Reviewed by:}

Maite Montero-Hadjadje, INSERM U982, France

David Cruz-Garcia, Centre for Genomic Regulation, Spain

Gustavo Egea, University of

Barcelona, Spain

*Correspondence:

José A. Martínez-Menárguez, Department of Cell Biology and Histology, Medical School, University of Murcia, 30100 Murcia, Spain. e-mail:jamartin@um.es
In neuroendocrine cells, prohormones move from the endoplasmic reticulum to the Golgi complex (GC), where they are sorted and packed into secretory granules. The GC is considered the central station of the secretory pathway of proteins and lipids en route to their final destination. In most mammalian cells, it is formed by several stacks of cisternae connected by tubules, forming a continuous ribbon. This organelle shows an extraordinary structural and functional complexity, which is exacerbated by the fact that its architecture is cell type specific and also tuned by the functional status of the cell. It is, indeed, one the most beautiful cellular organelles and, for that reason, perhaps the most extensively photographed by electron microscopists. In recent decades, an exhaustive dissection of the molecular machinery involved in membrane traffic and other Golgi functions has been carried out. Concomitantly, detailed morphological studies have been performed, including $3 \mathrm{D}$ analysis by electron tomography, and the precise location of key proteins has been identified by immunoelectron microscopy. Despite all this effort, some basic aspects of Golgi functioning remain unsolved. For instance, the mode of intra-Golgi transport is not known, and two opposing theories (vesicular transport and cisternal maturation models) have polarized the field for many years. Neither of these theories explains all the experimental data so that new theories and combinations thereof have recently been proposed. Moreover, the specific role of the small vesicles and tubules which surround the stacks needs to be clarified. In this review, we summarize our current knowledge of the Golgi architecture in relation with its function and the mechanisms of intra-Golgi transport. Within the same framework, the characteristics of the GC of neuroendocrine cells are analyzed.

Keywords: golgi complex, neuroendocrine cells, morphology, transport vesicles, tubules, intra-golgi transport

\section{INTRODUCTION}

A century ago the Italian anatomist Camillo Golgi described a new organelle that nowadays bears his name, the Golgi apparatus or Golgi complex (GC) (Golgi, 1898). Using a silver impregnation method, the "black reaction," he found a reticular structure in neurons that he called "apparato reticolare interno." Due to the difficulties and variability inherent to the technique, it was not clear for decades whether this structure was anything more than an artifact. The electron microscope clearly demonstrated that, the GC is indeed a real organelle, which is composed of flattened cisternae surrounded by tubules and vesicles (Dalton and Felix, 1956). These first ultrastructural images obtained from ultrathin sections showed the exceptional complexity of the organelle and, consequently, high voltage electron microscopy and stereology were used to obtained 3D information (Rambourg et al., 1974). Ultrastructural immunocytochemical methods provide great impetus to the morpho-functional analysis of the GC through the precise location of key molecular components (Rabouille and Klumperman, 2005). Electron tomography has increased our knowledge of the 3D architecture of the GC (Ladinsky et al., 1999). Another advance has been the use of correlative light-electron microscopy, whereby cell organelles are visualized first by light microscopy in living cells transfected with fluorescent proteins, and then the same structures are identified under the electron microscope (Polishchuk et al., 2000; Mironov et al., 2008; van Rijnsoever et al., 2008). The combination of immunoelectron microscopy and electron tomography is a powerful approach for scrutinizing the secrets of this organelle (Zeuschner et al., 2006). In parallel to morphological approaches, biochemical and genetic analyses have described in detail the molecular machineries operating in the secretory/endocytic pathways.

The GC has two main functions. The first is the posttranslational modification of proteins and lipids arriving from the endoplasmic reticulum (ER), mainly their glycosylation. The second function is the concentration, packing, and export of these modified products to the final destination in or outside of the cell. Thus, the GC is at the same time an efficient glycan factory and a post office. Helping to carry these functions is a surprisingly complex array of membranes equipped with an accurate machinery. Despite the large volume of incoming and outgoing traffic, it is able to maintain its architecture, although it is also flexible enough to disassemble and reassemble under certain conditions, such as mitosis. In neuroendocrine cells, prohormones are frequently glycosylated and proteolytically processed before being sorted into secretory granules (reviewed in Vázquez-Martínez et al., 2012). A summary of the current knowledge on the morphology of this 
organelle and early steps of the secretory pathway (i.e., ER-Golgi and intra-Golgi transport) is given below. Post-Golgi events, such as secretory granule formation, and other aspects of the Golgi functions are omitted in this description and can be found in excellent reviews elsewhere.

\section{MORPHOLOGY OF THE GOLGI RIBBON}

In mammalian cells, this organelle consists of a pile of flat, disklike membranes, the cisternae (Figures 1-3). This pile of cisternae is called the Golgi stack. The number of cisternae per stacks varies between different organisms but is characteristic of each species, usually numbering between 3 and 11 (Rambourg and Clermont, 1997). The diameter of the cisternae is also cell type-dependent, and is usually $0.5-1 \mu \mathrm{m}$ (Weidman et al., 1993). The lumen of the cisternae is usually quite narrow $(10-20 \mathrm{~nm})$, allowing the interaction of the glycosylation enzymes present in its membranes and the cargo. Typically, cisternae are of uniform thickness in the central part but dilated near the lateral rims. In secretory cells, cisternae may show distensions filled with a material of low electron density, known as pro-secretory granules. These elements can be observed in the trans side alone (prolactin cells) or in all the cisternae, although, in the latter case, their size increases in the trans direction (Rambourg and Clermont, 1997). Cisternae may show small (fenestrae) and large holes, which are sometimes aligned to form wells (Ladinsky et al., 1999). Usually, such wells are filled with vesicles and exposed to both the cis and lateral sides of the stacks (Ladinsky et al., 1999). Fenestrations are less abundant in the medial cisternae of the stack and increase in both cis and trans directions.

Early histochemical and immunoelectron microscopical analysis demonstrated that the Golgi stack is polarized. Thus, based on the distribution of resident proteins, the Golgi stack can be divided into three regions: cis, medial, and trans. Glycosyltransferases, sugar nucleotide transporters, and many other Golgi proteins are preferentially found in one of these sub compartments. However, the resident proteins are not restricted to a few cisternae, but exhibit a gradient of concentration through out the cisternae of the stack, suggesting a state of dynamic equilibrium (Rabouille et al., 1995).

The GC of most mammalian cells is formed of several stacks that are laterally interconnected by tubules forming the Golgi ribbon (Rambourg et al., 1979; Rambourg and Clermont, 1997; Marsh et al., 2001) (Figures 1 and 2A). Thus, although it is not always apparent, the stacks observed in typical electron microscopic images of the Golgi area, belong to the same ribbon. Due to their appearance, the pile of cisternae and the lateral tubular network are called the compact and non-compact zones, respectively. Usually, the tubules connect cisternae located in the same positions in the respective stacks. However, heterotypic connections, even between the cis-most and trans-most cisternae of adjacent stacks,

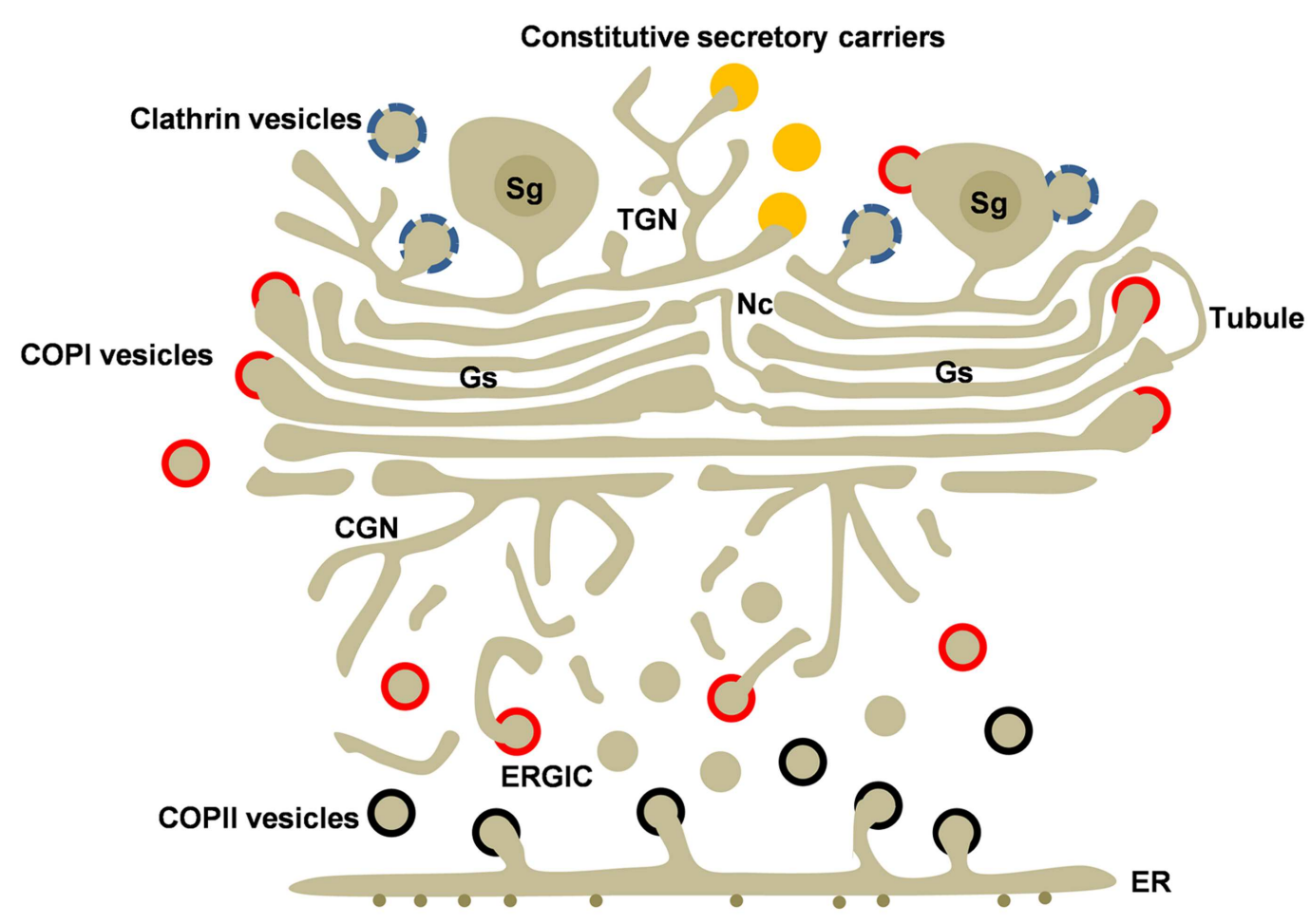

FIGURE 1 | Golgi structure and transport carriers in secretory cells. The Golgi ribbon is formed by adjacent Golgi stacks (Gs) separated by non-compact regions (Nc) containing tubules and vesicles. Golgi stacks are connected to the cis and trans Golgi networks (CGN and TGN). Newly synthesized cargo leaves the endoplasmic reticulum (ER) by COPIl-coated vesicles (black). COPI-coated (red) vesicles mediate recycling from the Golgi and the ERGIC. Transport carriers at the TGN include clathrin-coated vesicles (blue), regulated secretory granules $(\mathrm{Sg})$, and the poorly understood constitutive secretory carriers (orange) Clathrin and COPI coats are also associated to secretory granules. Heterotypic and homotypic tubular connections between cisternae may be involved in anterograde and/or retrograde intra-Golgi transport. 

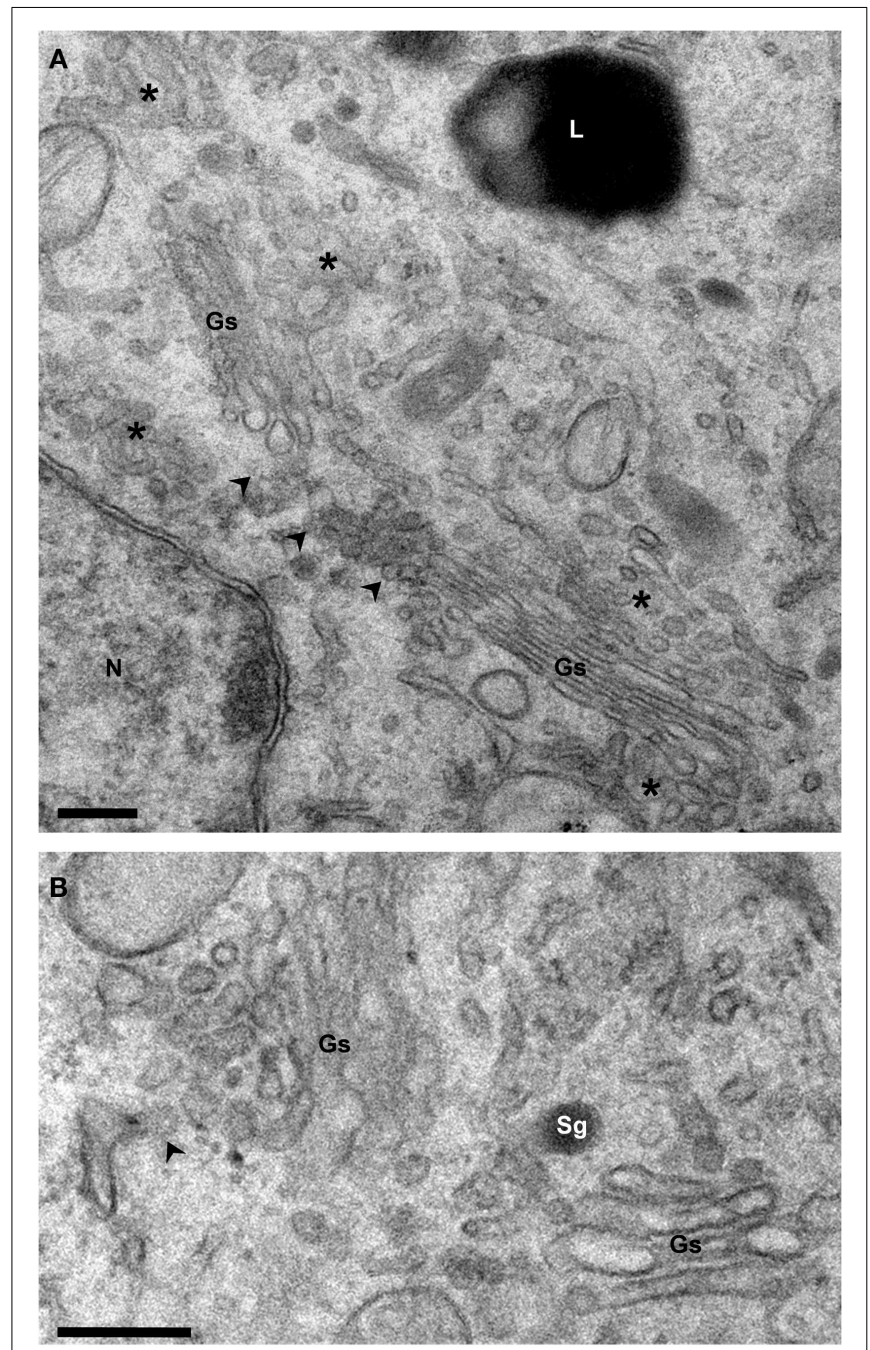

FIGURE 2 | Structure of the Golgi ribbon. Electron micrographs of Epon-embedded PC12 cells. (A) The Golgi stacks (Gs) are surrounded by tubule-vesicular elements (asterisks). Arrowheads point to the non-compact area of the ribbon which connects the stacks laterally. (B) The cis and trans sides of the stacks are identified by the presence of ER exit sites (arrowhead) and secretory granules (Sg), respectively. Gs, Golgi stack; L, Lysosome; N, Nucleus. Bars, $200 \mathrm{~nm}$.

are abundant in some cell types (Rambourg and Clermont, 1997; Vivero-Salmerón et al., 2008). Frontal views of cisternae point to lateral networks of tubules emerging from the fenestrated rims (Weidman et al., 1993). Some of these tubular membranes fuse with the same cisterna, whereas others grow toward the cytoplasm. A single cisterna may have tubules oriented toward the cis and trans sides (Ladinsky et al., 1999). Many tubules, however, extend laterally and fuse with tubules from adjacent Golgi stacks, forming the tubular network that bridges adjacent stacks.

Usually, the ribbon is located close to the nucleus, around the microtubule organizing centers (MTOC), and the spatial configuration of the GC is closely related to the arrangement and orientation of the microtubules. The maintenance of the Golgi ribbon strongly depends on the microtubules and the action of motor proteins (Egea and Rios, 2008). Microtubule de-polymerizing agents such as nocodazole induce fragmentation of the ribbon into mini stacks (Storrie et al., 1998). In fact, the GC acts as a secondary MOTC. Golgi organization also depends on the actin cytoskeleton (Egea et al., 2006).

The structure of the ribbon is also supported by the socalled Golgi matrix, a ribosome-free area surrounding the cisternae (Xiang and Wang, 2011). This matrix can be visualized as small fibers connecting the cisternae (Mollenhauer and Morre, 1998) and also connecting the Golgi membranes and transport vesicles (Orci et al., 1998). The matrix is formed by structural proteins, some of them identified as auto-antigens and others isolated from detergent-insoluble salt-resistant Golgi fractions (Slusarewicz et al., 1994). These components include Golgi reassembly stacking proteins (GRASPs) and golgins (Xiang and Wang, 2011). These proteins are very dynamic and cycle between membrane-associated and a cytoplasmic forms.

The morphology of the GC (the number of cisternae per stack, the number of fenestrations, the complexity of associated tubulevesicular elements, etc.) is cell type specific and depends on the activity of the cell. The level of cargo reaching the GC is an important factor in Golgi appearance. In general, when the input of cargo is low, the GC decreases in size and becomes larger when the synthetic activity is stimulated (Clermont et al., 1993; Taylor et al., 1997; Aridor et al., 1999; Glick, 2000). The relationship between cell activity and Golgi organization was clearly shown in prolactin cells. When the activity of these cells is reduced by removing the litters from lactating rats, the number of cisternal fenestrations and peri-Golgi vesicles increases concomitantly with a reduction in the number of Golgi tubules and mature secretory granules (Rambourg et al., 1993).

\section{CIS AND TRANS GOLGI NETWORK}

The Golgi stack is flanked by two tubule-vesicular networks located at the cis and trans sides, which represent the entry and exit sides of the stack, respectively (Figure 1). At the cis-side, the cis-Golgi network (CGN) is involved in ER-Golgi transport. At the trans side, the trans Golgi network (TGN) receives and packs proteins and lipids that have traversed the stack and deliver them to their final destinations.

The CGN is formed of tubules connected to the first Golgi cisterna (Sesso et al., 1994; Rambourg and Clermont, 1997). This element is well developed in some cell types such as spermatids (Vivero-Salmerón et al., 2008) but less so in others, such as prolactin cells (Rambourg and Clermont, 1997). In early electron microscopical studies, these tubules were selectively identified by using reducing osmic for prolonged times. The functional relationship of this tubular network connected to the stack (the CGN) and ER-derived pre-Golgi elements [intermediate compartment (IC), see below] remains to be established.

Trans Golgi network is involved in the final steps of protein glycosylation and maturation and in the sorting of products to the apical and basolateral plasma membranes, early and late endosomes, and secretory granules (Griffiths and Simons, 1986; Keller and Simons, 1997; De Matteis and Luini, 2008). In neuroendocrine cells, the secretory proteins are concentrated in secretory granules that can be rapidly released after stimulation (Kelly, 1985). This 


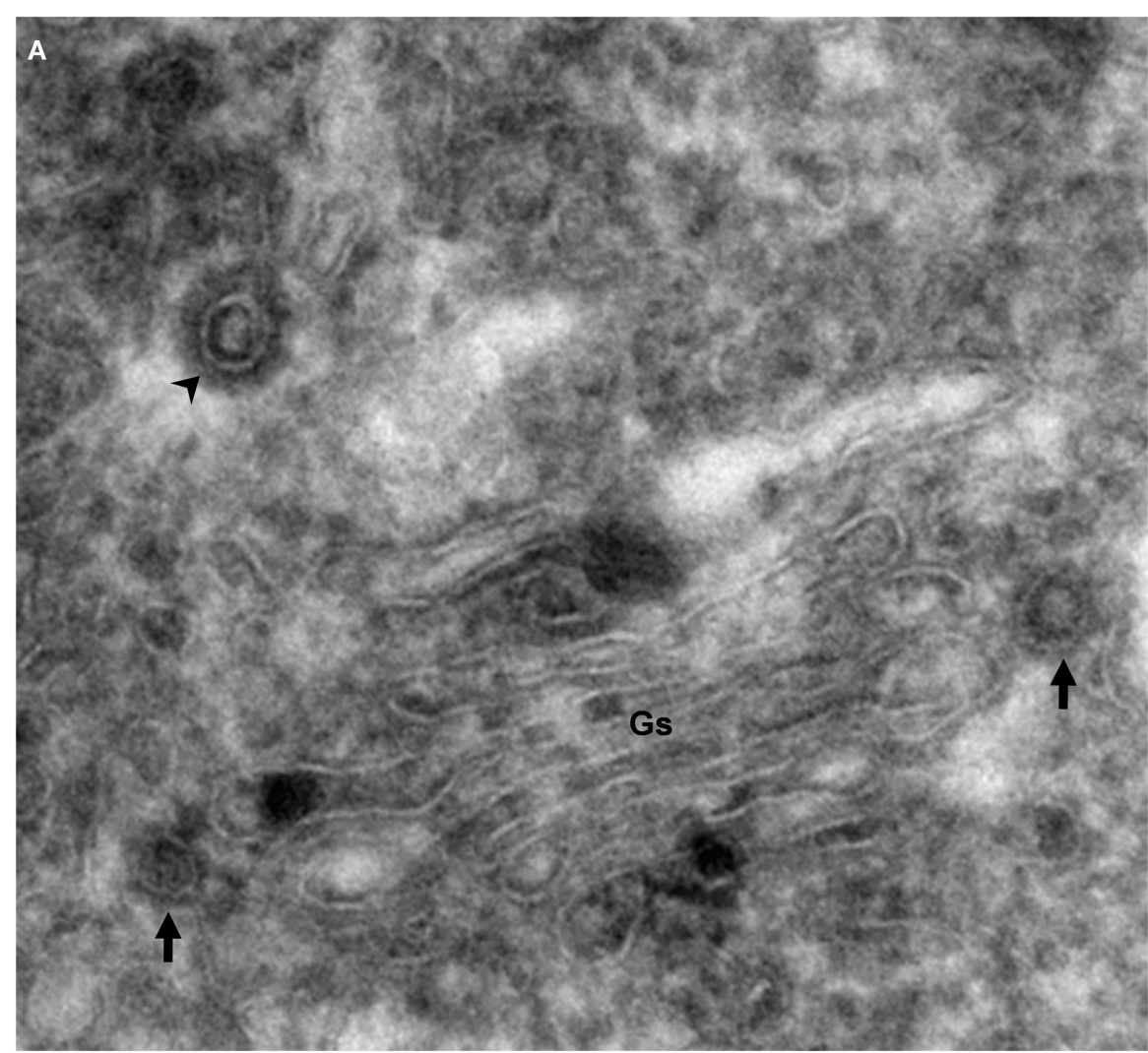

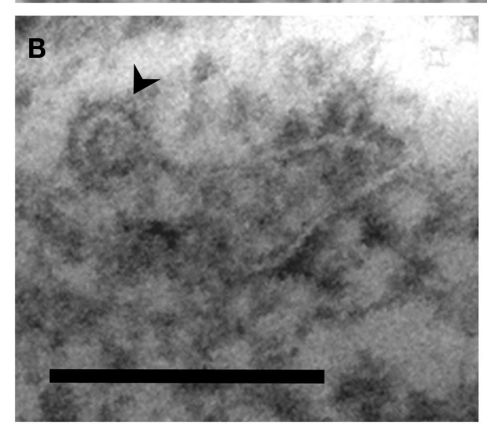

FIGURE 3 | Coated vesicles and buds. Electron micrographs of cryosections of PC12 cells. Using this methodology, membranes appear negatively stained, whereas coats are identified as electron dense areas around vesicles and buds. (A) COP- (arrows) and clathrin-coated

(arrowhead) vesicles are observed in the lateral and trans Golgi sides,

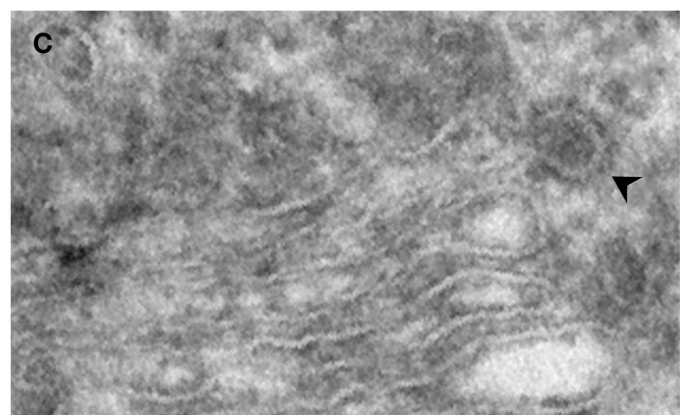

respectively. Note the different thickness of these coats. (B) COPII-coated bud associated to the endoplasmic reticulum (arrowhead). (C) COPI-coated bud in the lateral rim of cisterna (arrowhead). COPII- and COPI-coated buds are identified by their locations because the thickness of these coats is identical. Bar, $200 \mathrm{~nm}$. regulated secretory pathway co-exists with the constitutive secretory pathway that is common to all cell types (Arvan and Castle, 1998). The sorting process can take place in the TGN (sorting-forentry) or in immature secretory granules (sorting-by-retention) (Borgonovo et al., 2006). Different carriers and associated molecular machineries may be used for different routes (Traub and Kornfeld, 1997). Structurally, the TGN is formed of a large tubular network in continuity with the trans-most cisterna of the Golgi stack (Griffiths et al., 1985; Clermont et al., 1995). This is not always evident and, in some cell types, TGN can be found some distance from the stack (Clermont et al., 1995). The TGN can vary significantly in both size and composition, depending on the amount and type of cargo, and is reduced or absent in cells producing secretory granules in contrast with cells with an extensive lysosomal system (Clermont et al., 1995).

\section{VESICLES}

The Golgi stack is surrounded by a high number of $50-100 \mathrm{~nm}$ vesicles, the smallest ones at the cis-side and lateral rims, and the largest ones at the trans side (Marsh et al., 2001). Many of these vesicles have a coat, an electron dense proteinaceous layer on the cytoplasmic leaflets of their membranes (Figure 3). These coats are also found in certain areas of the secretory/endocytic compartments, which represent forming vesicles. Three types of 
coat complex (COPI, COPII, and clathrin) have been identified and characterized. COPI- and COPII-coated vesicles are almost identical under the electron microscope. The overall size and coat thickness are 50-60 and $10 \mathrm{~nm}$, respectively. COPII-coated buds are restricted to the ER, while COPI-coated buds are found in preGolgi and Golgi membranes (Griffiths et al., 1985; Oprins et al., 1993; Orci et al., 1997; Martinez-Menárguez et al., 2001; Rabouille and Klumperman, 2005). The trans-most cisternae of the Golgi and the TGN contains another type of coat, the clathrin coat (Pearse and Robinson, 1990) which is also found in the plasma membrane and endosomes. Clathrin-coated vesicles are unambiguously identified by their size $(100 \mathrm{~nm})$ and the thickness of the coat (18 nm) (Orci et al., 1984; Heuser and Kirchhausen, 1985; Kirchhausen et al., 1986; Oprins et al., 1993; Ladinsky et al., 2002). Interestingly, clathrin and COPI coats are also observed in forming secretory granules (Martínez-Menárguez et al., 1999).

Vesicles represent the best known type of transport intermediate. A huge amount of information has been accumulated on the molecular machinery involved in regulation of intercompartmental transport in the secretory pathway. Most data refer to vesicles as transport carriers but it can be assumed that the same or similar mechanisms operate in other carriers. While the formation of vesicles and the selection of cargo depend on the coat machinery, the specific targeting and fusion of the carriers with the target membranes depend on tethering factors, Rab and SNARE (soluble $N$-ethylmaleimide-sensitive factor attachment protein receptors) proteins, and other accessory proteins (Bonifacino and Glick, 2004).

SNARE proteins are involved in docking and the specific fusion of transport intermediates with the target membranes (Bonifacino and Glick, 2004; Hong, 2005; Jahn and Scheller, 2006). The SNAREs associated with vesicles (or other transport intermediates) and target membranes have been named $\mathrm{v}$ - and $\mathrm{t}$ SNARE, respectively. SNAREs have also been divided into R- and $\mathrm{Q}-\mathrm{SNAREs}$, according to the central residue (R/Gln or $\mathrm{Q} / \mathrm{Arg}$, respectively) of the SNARE domain, a conserved region of 60 70 residues found in all members of this family. Commonly, v-SNARE and t-SNARE are R-SNARE and Q-SNARE, respectively. Interaction between one v-SNARE and two/three t-SNAREs induces the formation of the trans-SNARE complex, which catalyzes the fusion of the membranes. After fusion, a cis-SNARE complex is formed in the target membrane, which is later disassembled by the action of the cytosolic proteins $\alpha$-SNAP (soluble $N$-ethylmaleimide-sensitive factor attachment protein) and the ATPase NSF ( $N$-ethylmaleimide-sensitive factor). Now, v-SNARE can be transported back to the donor compartment to be reused. SNARE proteins are sufficient to drive membrane fusion so that they are considered the minimal membrane fusion machinery. Two SNARE complexes have been implicated in intra-Golgi transport (Malsam and Söllner, 2011). One complex is formed of v-SNARE GS15 and the t-SNAREs syntaxin5, GOS28, and Ykt6, and is involved in COPI-dependent intra-Golgi transport. The second complex is formed of ${ }^{-S}$-SNARE rBet1 and the t-SNAREs syntaxin 5, membrin (GS27), ERS24/Sec22. This second complex has also been implicated in ER-to-Golgi and intra-Golgi transport (Volchuk et al., 2000). SNARE complex assembly is regulated by SM (Sec1/Munc18) proteins, a family of cytosolic proteins. Sly1 I is the only member of this family operating in the ER-Golgi area (Laufman et al., 2009), whereas Munc18-1 is involved in the exocytosis of dense-core granules in neuroendocrine cells (Burgoyne et al., 2009).

Rab proteins are a family of small GTPases that regulate membrane transport by recruiting effectors, including sorting adaptors, tethering factors, kinases, phosphatases, and motor proteins (Jahn and Scheller, 2006; Stenmark, 2009). Rab proteins switch between an active form (GTP-bound) and a cytosolic inactive form (GDPbound). They have been implicated in vesicle budding, uncoating, mobility, and transport. Rab proteins in the GTP-bound form are reversibly associated with membranes by geranylgeranyl groups. The replacement of GDP by GTP is facilitated by guanine nucleotide exchange factors (GEFs), and their low intrinsic GTPase activity is enhanced by GTPase-activating proteins (GAP). Rab protein is a large family, including more than 60 members in humans, which are specifically associated with distinct compartments and transport events (Stenmark, 2009). Interestingly, the specific membrane recruitment of Rabs has recently been demonstrated to depend on the activity of GEFs (Blümer et al., 2013). The Golgi-associated Rab family playing a key role in Golgi maintenance and functioning includes Rab1, Rab2, Rab6, Rab33B, Rab18, and Rab43 (Liu and Storrie, 2012). Rab3 (A-D), Rab11, Rab18, Rab26, Rab27 (A,B), and Rab37 are involved in regulated secretion (Fukuda, 2008; Stenmark, 2009). Rab3A, Rab11, Rab18, and Rab27A regulate exocytosis in neuroendocrine cells by interacting directly with secretory vesicles (Vázquez-Martínez and Malagón, 2011). A few GEFs and GAPs for secretory Rabs have been identified. The specific role of secretory Rabs in the formation and maturation of the secretory vesicles, and their docking and fusion with the plasma membrane, remains controversial.

Tethering factors are a group of membrane-associated proteins or multi-subunit complexes that link transport vesicles with the target membranes to ensure correct docking and fusion. In addition to tethering, they play a role in Golgi stacking and form the Golgi matrix. They have been classified into three classes: oligomeric complexes that work as Rab effectors and bind SNARE, oligomeric complexes that function as GEFs for Rab proteins and, finally, coiled-coil tethers (Sztul and Lupashin, 2009). Golgiassociated members of the last group are called golgins. The golgin family includes p115, a protein believed to be involved in tethering COPII vesicles to pre-Golgi membranes, transport from these elements to the cis-Golgi and intra-Golgi transport. GM130 is another coiled-coil protein associated with the cis-Golgi. GM130 and p115 are also components of the Golgi matrix. Apart from their role as tethers, they are involved, together with other members of the golgin and GRASP families such as giantin and GRASP65, in maintaining the stacked morphology of the cisterna and the Golgi ribbon (De Matteis et al., 2008). NECC1 (neuroendocrine long coiled-coil protein 1) is a new component of this family, which is mainly present in neuroendocrine tissues (Cruz-Garcia et al., 2007). NECC1 is the first long coiled-coil protein described that has a role as a negative modulator of the regulated secretion in neuroendocrine cells (Cruz-García et al., 2012). Dsl1, conserved oligomeric Golgi (COG), and transport protein particle (TRAPP) are multi-subunit complexes associated with the GC (Sztul and Lupashin, 2009). Dsl1 is a three unit complex involved 
in Golgi-to-ER transport, where it acts to tether COPI vesicles. The COG complex formed of eight subunits ( $\operatorname{Cog} 1-8)$ found at the cis and medial Golgi cisternae is believed to be involved in transport to the Golgi and the intra-Golgi recycling of Golgi resident proteins (Miller and Ungar, 2012). TRAPP is another multi-subunit complex that works as tethering factor (Sacher et al., 2008). At least two TRAPP complexes exist in mammals. TRAPPI tethers COPIIcoated vesicles and mediates ER-to-Golgi transport (Barrowman et al., 2010). TRAPII has been involved in intra-Golgi transport, post-Golgi traffic, endosome-to-Golgi, and autophagy (Yu and Liang, 2012). They work as GEF for Rabl and the activation of this GTPase might recruit other tethers (Sztul and Lupashin, 2009).

Some lipidic species, such as diacylglycerol, phosphatidic acid and lysophosphatidic acid, and enzymes associated with their metabolism play a key role in carrier formation by regulating the curvature of membranes. Diacylglycerol has been implicated in the formation of post-Golgi carriers and is necessary to recruit protein kinase $\mathrm{D}$, a regulator of the fission of transport carriers (Bard and Malhotra, 2006). Diacylglycerol has also seen to be involved in Golgi-to-ER retrograde transport mediated by tubules (Fernández-Ulibarri et al., 2007). Phosphatidic acid, which is generated by phospholipase D2, is involved in COPI vesicle formation (Yang et al., 2008). This phospholipid is necessary to maintain the structure of the GC and secretion in neuroendocrine cells (Siddhanta et al., 2000). Lysophosphatidic acid generated by the enzyme phospholipase A2 has been involved in the retrograde transport mediated by tubules (de Figueiredo et al., 2000; Brown et al., 2003). This enzyme is involved in the formation of tubular continuities between cisternae (San Pietro et al., 2009) and tubular transport intermediates at the TGN (Schmidt et al., 2010). Interestingly, two lipid-modifying enzymes, lysophosphatidic acid acyltransferase $\gamma$ and phospholipase A2- $\alpha$, which promote or inhibit COPI fission, respectively, work together, regulating the morphology of Golgi carriers (vesicles vs. tubules) (Yang et al., 2011).

\section{THE GOLGI COMPLEX OF NEUROENDOCRINE CELLS}

The hypothalamus-hypophysis system is the most important and well-known neuroendocrine system. Important clues on Golgi functioning have been obtained by studying the GC of the pituitary gland. In addition, neuroendocrine cell lines, such as corticotropic tumor AtT20, pheochromocytoma PC12, and frog melanotrope cells, provide important clues as regards secretory granule formation and regulation (Morvan and Tooze, 2008). Thus, the discovery that immature secretory granules originated from Golgi cisternae was made in mammotroph cells (Farquhar, 1961). In the same cell type it was also found that that there is a step during which secretory material is condensed in the GC (Smith and Farquhar, 1966). AtT20 cells have been used to show that there are different routes from the GC to the plasma membrane (Gumbiner and Kelly, 1982). However, detailed morphological studies of the Golgi ribbon of neuroendocrine cells, with some exceptions, are scarce. The morphology of the GC and the formation of secretory granules in prolactin cells were described in early microscopic studies. In these cells, the Golgi ribbon forms a hollow sphere in the perinuclear area. The stacks of prolactin cells have four to five (mostly flattened) cisternae and show a reduced CGN and TGN (Rambourg and Clermont, 1997). The trans cisternae show distensions that are gradually transformed into tubular progranules at the trans face and are finally condensed into compact polymorphous granules (Clermont et al., 1993). As indicated above, the morphology of this compartment is strongly dependent on cell activity (Rambourg et al., 1993). Many other cells of the anterior pituitary gland have not been extensively studied, although some of these cell types have a spherical GC, with cis and trans side representing the outer and inner part of this sphere, respectively (Watanabe et al., 2012).

\section{ER-TO-GOLGI TRANSPORT}

Newly synthesized proteins and lipids in general, and prohormones in neuroendocrine cells, exit the ER in specific places of this compartment, called ER exit sites (ERES). These places are formed by tubular buds of different length containing a COPII coat (Sesso et al., 1994; Bannykh et al., 1996; Zeuschner et al., 2006), which assists in the deformation of ER membranes into vesicles containing membrane and soluble cargo en route to the GC (Barlowe et al., 1994). The COPII coat complex is formed of five soluble proteins: Sec23, Sec24, Sec13, Sec31, and Sar1 (Barlowe et al., 1994; Bickford et al., 2004). Formation of the COPII coat begins with the recruitment of the GTPase Sar1 in ER membranes. This binding depends on the activation of this GTPase by Sec12, a GEF present in ER membranes (Jensen and Schekman, 2011). During this process some proteins are selectively recruited into COPII vesicles (Barlowe, 1998, 2003), whereas others enter unspecifically, a process known as bulk flow (Martínez-Menárguez et al., 1999). Sorting of the transmembrane cargo depends on Sec24 (Mancias and Goldberg, 2008). The soluble cargo present in the lumen of the ER binds to cargo receptors, such as ER-Golgi IC (ERGIC)53, p24, and the Erv families (Szul and Sztul, 2011). These cargo receptors cycle between the ER and Golgi and also are included in recycling COPI vesicles. The p24 family comprises $8-10$ isoforms and a subset of these proteins is up-regulated, together with proopiomelanocortin, after the activation of neuroendocrine frog melanotrope cells (Strating et al., 2011). The size of COPII vesicles is regulated by ubiquitination of Sec31, allowing the formation of large COPII vesicles (Jin et al., 2012). After formation, COPII vesicles are quickly uncoated and fuse to each other to form the socalled ERGIC, IC, or vesicular-tubular clusters (VTCs), the first of these being the most used (Hauri and Schweizer, 1992; Farquhar and Hauri, 1997). This compartment was initially identified as tubule-vesicular membranes in which the cargo accumulates when cells are cultured at low temperatures $\left(15^{\circ} \mathrm{C}\right)$ (Saraste and Kuismanen, 1984; Schweizer et al., 1990). This compartment is located close to the GC and is also distributed throughout the cell (Lotti et al., 1992; Klumperman et al., 1998), and is associated to ERES (Bannykh et al., 1996). ERGIC is formed by vesicles and tubules, sometimes branched (Bannykh et al., 1996). Although adjacent to the ERES, ERGIC is an independent compartment and there is no continuity between them (Bannykh et al., 1998). ERGIC membranes do not have COPII coats but another type of coat complex, the COPI coat, which is involved in retrograde transport (see below). Thus, the presence of these coats can be used to discriminate between these closely related compartments. Whether the ERGIC is a stable compartment or a transitory element moving toward the GC is still a matter of debate (Ben-Tekaya et al., 
2005). The fact that all the proteins associated with this compartment cycle between the ER and Golgi argues against the idea that it is a stable compartment. ERGIC-53, a type I transmembrane protein of the lectin family, is the prototypical marker of this compartment (Zhang et al., 2009). However, in vivo experiments showed that ERGIC-53 is located in long-lived stationary elements connected by highly mobile elements (Ben-Tekaya et al., 2005), supporting the view that ERGIC is a stable compartment. ERGIC elements or ERGIC-derived carriers move to the Golgi area along the microtubule track guided by dynein motors, where they may fuse to each other to form the CGN or, conversely, fuse with a pre-existing cisterna (Presley et al., 1997).

\section{GOLGI-TO-ER TRANSPORT}

Organelle identity is determined by its composition, and its functional integrity is due to its ability to maintain this composition despite the continuous traffic between compartments. An important mechanism involved in this process is retrograde transport. In the early secretory pathway, ERGIC is the first place where this process occurs. Here, the presence of COPI coats ensure the recycling of proteins to the ER while anterograde cargo is separated and concentrated (Scales et al., 1997; Klumperman et al., 1998; Martínez-Menárguez et al., 1999; Shima et al., 1999; Stephens et al., 2000). The function of the COPI coats in the Golgi-toER retrograde transport of soluble and membrane proteins has been convincingly demonstrated (Letourneur et al., 1994). However, there are retrograde routes to the ER independent of COPI (Girod et al., 1999). It is also possible that a population of COPI vesicles is involved in anterograde transport across the Golgi stack (Orci et al., 1997).

COPI-coated vesicles are found in peripheral and central ERGIC elements, at cis and lateral Golgi sides (Oprins et al., 1993) and, occasionally, at the trans Golgi side/TGN (MartínezMenárguez et al., 1996). COPI-coated buds are observed at the lateral rims of cisternae, decreasing in number in a cis to trans direction (Ladinsky et al., 1999). COPI coats are formed of seven subunits $(\alpha, \beta, \beta, \gamma, \delta, \varepsilon, \zeta$-COP) assembled in the cytosol, the coatomer, and small GTPase ADP-ribosylation factors (Arf1). Arf1 belong to the Arf family, which is made up of six members in mammals (D'Souza-Schorey and Chavrier, 2006). Arfs 1-5 have been described at the ER-Golgi interface, where they may have redundant functions. Besides, it has been suggested that different pairs of Arfs may be necessary for each transport step (Volpicelli-Daley et al., 2005). Arf1 and 4 and Arfs 3-5 are associated to the cis and trans Golgi sides, respectively (Donaldson and Jackson, 2011). Arf 4 and 5 interact with calcium-dependent activator for secretion (CASP), regulating the formation of neuroendocrine secretory granules (Sadakata et al., 2010). Arf1-GDP is recruited to membranes by p23, a member of the p24 family (Gommel et al., 2001), and, once there, it is activated by a GEF. GTP-bound Arf1 is able to recruit coatomer en bloc to membranes. At the ERGIC and Golgi membranes, GBF1 (Golgi-associated BFA-resistant protein) is the major GEF for ARF1 during COPI vesicle formation and is the target of the drug brefeldin A (Kawamoto et al., 2002; GarciaMata et al., 2003), while Big1 and Big2 (BFA-inhibited GEF) are described as GEFs for Arf1 in the TGN and endosomes (Ishizaki et al., 2008). ArfGAPs stimulate the GTP hydrolysis of Arf, which has low intrinsic GTPase activity (Inoue and Randazzo, 2007). It has been postulated that this reaction triggers uncoating (Tanigawa et al., 1993); however, ArfGAP1 has also been described as a coatomer component and also as a sensor of membrane curvature, so the role of this protein is under discussion (Shiba and Randazzo, 2012). ArfGAP1, phosphatidic acid generated by phospholipase D and BARS (brefeldin A-ribosylated substrate) have been implicated in COPI vesicle fission (Yang et al., 2008).

Many transmembrane proteins transported into COPI vesicles bear di-lysine motifs at their C-terminus (Letourneur et al., 1994), including ERGIC-53 (Schindler et al., 1993). The coatomer subunits, $\alpha$ - and $\beta$ '-COP, directly bind this signal (Jackson et al., 2012). The p24 family of proteins is recruited by direct interaction of their cytoplasmic tail, which contains phenylalanine- and di-lysine-based signals, with $\gamma$-COP (Nickel et al., 1997; Béthune et al., 2006). Not all cargo incorporated in COPI vesicles has this sorting signal so that the cargo may require adaptors. This is the case with glycosylation enzymes (Popoff et al., 2011). One example of an adaptor for soluble proteins is the KDEL receptor, a transmembrane protein mostly present in the cis-Golgi and ERGIC, which interacts with the coatomer through a di-lysine motif in the cytosolic tail, whereas the luminal part interacts with soluble proteins bearing a K-D-E-L sequence found in many ER-resident proteins (Semenza et al., 1990; Majoul et al., 2001). In this way, soluble proteins that have escaped from the ER are retrieved.

As indicated above, it is possible that there are several subpopulations of COPI vesicles with different compositions and locations, each carrying out its specific functions (Moelleken et al., 2007). Indeed, $\gamma$ and $\zeta$-COP present two isoforms localized differently along the GC, enabling the existence of four types of coatomer, which may act in different routes and types of cargo (Popoff et al., 2011). Thus, this coat conforms versatile vesicles that may play different roles at the ER-Golgi interface (Orci et al., 1997; Shima et al., 1999; Malsam et al., 2005).

\section{INTRA-GOLGI TRANSPORT}

Once cargo has reached the GC, the manner in which it moves through the stack remains controversial, and two classical models have been proposed: vesicular transport and cisternal maturation. The first proposes that Golgi cisternae are static so that the cargo must use vesicles to move. The second model proposes that cisternae are dynamic structures that move from the cis to trans Golgi sides. Thus, according to this model, the entire cisterna is the carrier. The postulated roles of COPI vesicles in vesicular and cisternal maturation models are completely different, since they are regarded as being responsible for anterograde and retrograde transport, respectively.

Launched by Palade (1975), the vesicular transport model postulates that cisternae are stable compartments. Thus, cargo must leave one cisterna and move to an adjacent one in order to advance through the stack. This process is mediated by COPI vesicles. For decades this model was widely accepted since it was based on new experimental data, especially the analysis of cell-free systems and immunomicroscopical studies (Rothman and Fine, 1980; Orci et al., 1986; Barlowe et al., 1994). It provided a good explanation for the well-known compartmentalization of the Golgi resident enzymes (Roth and Berger, 1982; Dunphy et al., 1985). Besides, 
it was strongly supported by the discovery of COPI and COPII vesicles which, it was postulated, act sequentially in the early secretory pathway (Rothman and Wieland, 1996). It was clearly demonstrated that COPII vesicles are involved in ER exit (Barlowe et al., 1994), while COPI were identified in in vitro assays as being responsible for anterograde transport between cisternae (Orci et al., 1986). However, this model was questioned when a clear role for COPI vesicles in retrograde transport was demonstrated (Cosson and Letourneur, 1994; Letourneur et al., 1994). Even so, the model remained in force even when two types of COPI vesicle were seen to be involved in anterograde and retrograde transport in the Golgi stack (Orci et al., 1997). The weakest point of this model is that it does not explain how large cargo is transported.

A cisternal maturation model was postulated by Grasse (1957) based on early electron microscopy observations, but it was not until the early 1990s that it was re-considered (Bonfanti et al., 1998; Glick and Malhotra, 1998). According to this model, cisternae are formed at the cis-side of the GC by fusion of ER-derived membranes and then these newly formed cisternae move from the cis to the trans side. This model fits very well with the observation that the Golgi resident enzymes are not strictly compartmentalized through the Golgi stack (Nilsson et al., 1993; Rabouille et al., 1995). Furthermore, this model is able to explain the transport of large cargo, such as procollagen $(300 \mathrm{~nm}$ rigid rod) (Bonfanti et al., 1998) or algal scales (up to $1.5-2 \mu \mathrm{m}$ ) (Melkonian et al., 1991), which do not fit within 50-60 nm vesicles. During cisternal progression, Golgi resident enzymes must be packed into COPI vesicles and transported backwards. Thus, Golgi enzymes are not lost but recycled in a trans to cis direction, maintaining the polarity of the organelle (Glick et al., 1997). Immunocytochemical (Martinez-Menárguez et al., 2001; Mironov et al., 2001) and proteomic (Gilchrist et al., 2006) analyses of these vesicles showed that they are mostly devoid of anterograde transport markers but enriched in glycosylation enzymes. However, other studies on COPI vesicle composition provided conflicting results. Thus, the role of COPI vesicles remains controversial (Cosson et al., 2002). Life cell imaging studies in yeast involving direct real time visualization of cisternal maturation strongly support this model (Losev et al., 2006; Matsuura-Tokita et al., 2006).

Since neither of these models explains all the experimental data, a combination of the same models (dual model) as well as new models (rapid partitioning, kiss-and-run) have been proposed (reviewed in Glick and Luini, 2011). The cisternal maturation model seems to be more efficient, given that it seems easier to transport anterograde cargo using a large carrier (the cisterna) than to use many small vesicles between adjacent cisternae and repeat this process several times until reaching the TGN. However, these models are not mutually exclusive and a combination of both might serve (Pelham and Rothman, 2000). Cisternae may move slowly, whereas vesicles transport anterograde and retrograde cargo more rapidly. Large molecules may use the cisternal maturation mechanism, while small molecules can be transported using vesicular transport (Orci et al., 2000; Pelham and Rothman, 2000). In addition, other mechanisms might operate in this transport step as several new models postulate. According to the rapid partitioning model, the GC operates as a single compartment but contains processing and export domains of differing lipid composition, which allow the specific retention of resident enzymes and cargo proteins (Patterson et al., 2008). The cargo associates with these domains and then leaves the compartment from every level. However, this model has difficulty in explaining many previous observations including the well-known polarized distribution of glycosylation processing enzymes, the progression of procollagen and other cargo across the stack or the role of COPI vesicles. The kiss-and-run model, meanwhile, proposes that two cisternae may fuse to each other through narrow tubules, connecting their lumens transiently, and allowing the transit of anterograde and retrograde cargo before disconnection (Mironov and Beznoussenko, 2012). Given that specific retrograde transport is not necessary in this model, COPI might be involved in the fission process. It is also not clear how all the experimental data available concerning the role of COPI coats in retrograde transport fit this model.

Despite the abundance and development of Golgi-associated tubules, as described above, most models of intra-Golgi transport do not include a role for these elements. Tubules may act as intermediate transport carriers, alone or with vesicles, and in anterograde and retrograde transport (Griffiths, 2000; Mironov et al., 2003; Marsh et al., 2004; Trucco et al., 2004; MartínezAlonso et al., 2005, 2007; Vivero-Salmerón et al., 2008). In fact, it has recently been found that a similar mechanism involving COPI and lipid-modifying enzymes may regulate the formation of both types of carrier in the GC (Yang et al., 2011). With some exceptions, intercisternal tubular connections are scarce in control cells but increase when secretory activity is stimulated (Marsh et al., 2004; Trucco et al., 2004), supporting the view that tubules may be involved in anterograde transport when there is an excess of cargo. In fact, it has been postulated that all secretory compartments are connected by tubules and the cargo moves along this pathway like food through the gut (Griffiths, 2000). Supporting this idea, although unusual, a Golgi stack formed by a single cisterna arranged helically and direct connections between the Golgi cisternae and the ER have been described (Tanaka et al., 1986). In order to clarify the role of tubules, it is first necessary to determine their composition, which is a difficult task. The number of tubules can be increased by the use of the fungal drug brefeldin A. Nowadays it is well accepted that brefeldin A-induced tubules are involved in Golgi-to-ER transport. Although this system is artificial, it is believed that brefeldin A intensifies a process that occurs naturally (Lippincott-Schwartz et al., 1990). Tubules can also be enhanced by lowering the temperature (Martínez-Alonso et al., 2005, 2007). These tubules exclude anterograde and retrograde cargo but recruit Golgi resident enzymes and a specific set of Rab and SNARE proteins involved in intra-Golgi transport (Martínez-Alonso et al., 2005, 2007). Thus, these induced tubules may be indicative of the recycling mechanisms of Golgi enzymes postulated by the cisternal maturation model.

\section{CONCLUDING REMARIS}

The GC has fascinated scientists for more than a century. Although it is without doubt the most photographed cell structure, it still retains most of its mystery. What is the reason for its beautiful architecture? Why does it form a ribbon in most cells? What are that the functions of the tubular networks? Do vesicles and tubules 
have specific functions? Is there a single mode of intra-Golgi transport? Do COPI vesicles take part in anterograde transport? Is the ERGIC a real compartment? These and many other questions remain unanswered, which, in itself, is surprising, given the intense research and the large number of research groups working in the field. It is to be hoped that new approaches and research models will help fill the gaps in our knowledge of this beautiful organelle.

\section{REFERENCES}

Aridor, M., Bannykh, S. I., Rowe, T., and Balch, W. E. (1999). Cargo can modulate COPII vesicle formation from the endoplasmic reticulum. J. Biol. Chem. 274, 4389-4399.

Arvan, P., and Castle, D. (1998). Sorting and storage during secretory granule biogenesis: looking backward and looking forward. Biochem. J. 332(Pt 3), 593-610.

Bannykh, S. I., Nishimura, N., and Balch, W. E. (1998). Getting into the Golgi. Trends Cell Biol. 8, 21-25.

Bannykh, S. I., Rowe, T., and Balch, W. E. (1996). The organization of endoplasmic reticulum export complexes. J. Cell Biol. 135, 19-35.

Bard, F., and Malhotra, V. (2006). The formation of TGN-to-plasmamembrane transport carriers. Annu. Rev. Cell Dev. Biol. 22, 439-455.

Barlowe, C. (1998). COPII and selective export from the endoplasmic reticulum. Biochim. Biophys. Acta 1404, 67-76.

Barlowe, C. (2003). Signals for COPIIdependent export from the ER: what's the ticket out? Trends Cell Biol. 13, 295-300.

Barlowe, C., Orci, L., Yeung, T., Hosobuchi, M., Hamamoto, S., Salama, N., et al. (1994). COPII: a membrane coat formed by Sec proteins that drive vesicle budding from the endoplasmic reticulum. Cell 77, 895-907.

Barrowman, J., Bhandari, D., Reinisch, K., and Ferro-Novick, S. (2010). TRAPP complexes in membrane traffic: convergence through a common Rab. Nat. Rev. Mol. Cell Biol. 11, 759-763.

Ben-Tekaya, H., Miura, K., Pepperkok, R., and Hauri, H. P. (2005). Live imaging of bidirectional traffic from the ERGIC. J. Cell Sci. 118, 357-367.

Béthune, J., Kol, M., Hoffmann, J., Reckmann, I., Brugger, B., and Wieland, F. (2006). Coatomer, the coat protein of COPI transport vesicles, discriminates endoplasmic reticulum residents from p24 proteins. Mol. Cell. Biol. 26, 8011-8021.

Bickford, L. C., Mossessova, E., and Goldberg, J. (2004). A structural view of the COPII vesicle coat. Curr. Opin. Struct. Biol. 14, 147-153.
Blümer, J., Rey, J., Dehmelt, L., Mazel, T., Wu, Y. W., Bastiaens, P., et al. (2013). RabGEFs are a major determinant for specific Rab membrane targeting. J. Cell Biol. 200, 287-300.

Bonfanti, L., Mironov, A. A. Jr., Martinez-Menarguez, J. A., Martella, O., Fusella, A., Baldassarre, M., et al. (1998). Procollagen traverses the Golgi stack without leaving the lumen of cisternae: evidence for cisternal maturation. Cell 95, 993-1003.

Bonifacino, J. S., and Glick, B. S. (2004). The mechanisms of vesicle budding and fusion. Cell 116, 153-166.

Borgonovo, B., Ouwendijk, J., and Solimena, M. (2006). Biogenesis of secretory granules. Curr. Opin. Cell Biol. 18, 365-370.

Brown, W. J., Chambers, K., and Doody, A. (2003). Phospholipase A2 (PLA2) enzymes in membrane trafficking: mediators of membrane shape and function. Traffic 4, 214-221.

Burgoyne, R. D., Barclay, J. W., Ciufo, L. F., Graham, M. E., Handley, M. T., and Morgan, A. (2009). The functions of Munc18-1 in regulated exocytosis. Ann. N. Y. Acad. Sci. 1152, 76-86.

Clermont, Y., Rambourg, A., and Hermo, L. (1995). Trans-Golgi network (TGN) of different cell types: three-dimensional structural characteristics and variability. Anat. Rec. 242, 289-301.

Clermont, Y., Xia, L., Rambourg, A., Turner, J. D., and Hermo, L. (1993). Structure of the Golgi apparatus in stimulated and nonstimulated acinar cells of mammary glands of the rat. Anat. Rec. 237, 308-317.

Cosson, P., Amherdt, M., Rothman, J. E., and Orci, L. (2002). A resident Golgi protein is excluded from peri-Golgi vesicles in NRK cells. Proc. Natl. Acad. Sci. U.S.A. 99, 12831-12834.

Cosson, P., and Letourneur, F. (1994). Coatomer interaction with di-lysine endoplasmic reticulum retention motifs. Science 263, 1629-1631.

Cruz-García, D., Díaz-Ruiz, A., Rabanal-Ruiz, Y., Peinado, J. R., Gracia-Navarro, F., Castaño, J. P., et al. (2012). The Golgi-associated long coiled-coil protein NECC1 participates in the control of the

\section{ACKNOWLEDGMENTS}

The work in this review was supported by grants from the Ministerio de Ciencia e Innovación (Spain) Consolider COAT CSD2009-00016) and Fundación Séneca de la Comunidad Autónoma de la Región de Murcia (04542/GERM/06) to José A. Martínez-Menárguez and a grant from the University of Valencia (UV-INV-AE11-41831) to Mónica Tomás.

regulated secretory pathway in $\mathrm{PC} 12$ cells. Biochem. J. 443, 387-396.

Cruz-Garcia, D., Vazquez-Martinez, R., Peinado, J. R., Anouar, Y., Tonon, M. C., Vaudry, H., et al. (2007). Identification and characterization of two novel (neuro)endocrine long coiled-coil proteins. FEBS Lett. 581, 3149-3156.

Dalton, A. J., and Felix, M. D. (1956). A comparative study of the Golgi complex. J. Biophys. Biochem. Cytol. 2, 79-84.

de Figueiredo, P., Drecktrah, D., Polizotto, R. S., Cole, N. B., LippincottSchwartz, J., and Brown, W. J. (2000). Phospholipase A2 antagonists inhibit constitutive retrograde membrane traffic to the endoplasmic reticulum. Traffic 1, 504-511.

De Matteis, M. A., and Luini, A. (2008). Exiting the Golgi complex. Nat. Rev. Mol. Cell Biol. 9, 273-284.

De Matteis, M. A., Mironov, A., and Beznoussenko, V. (2008). “The Golgi ribbon and the function of the golgins," in The Golgi Apparatus, eds A. A. Mironov and M. Pavelka (Wien: Springer-Verlag), 223-246.

Donaldson, J. G., and Jackson, C. L. (2011). ARF family G proteins and their regulators: roles in membrane transport, development and disease. Nat. Rev. Mol. Cell Biol. 12, 362-375.

D'Souza-Schorey, C., and Chavrier, P. (2006). ARF proteins: roles in membrane traffic and beyond. Nat. Rev. Mol. Cell Biol. 7, 347-358.

Dunphy, W. G., Brands, R., and Rothman, J. E. (1985). Attachment of terminal $\mathrm{N}$-acetylglucosamine to asparagine-linked oligosaccharides occurs in central cisternae of the Golgi stack. Cell 40, 463-472.

Egea, G., Lazaro-Dieguez, F., and Vilella, M. (2006). Actin dynamics at the Golgi complex in mammalian cells. Curr. Opin. Cell Biol. 18, 168-178.

Egea, G., and Rios, R. M. (2008). "The role of the cytoskeleton in the structure and function of the Golgi apparatus," in The Golgi Apparatus, eds A. A. Mironov and M. Pavelka (Wien: Springer-Verlag), 270-300.

Farquhar, M. G. (1961). Origin and fate of secretory granules in cells of the anterior pituitary gland. Trans. N. Y. Acad. Sci. 23, 346-351.

Farquhar, M. G., and Hauri, H. P. (1997). "Protein sorting and vesicular traffic in the Golgi apparatus," in The Golgi Apparatus, eds E. G. Berger and J. Roth (Basel: Birkhauser Verlag), 63-129.

Fernández-Ulibarri, I., Vilella, M., Lazaro-Dieguez, F., Sarri, E., Martinez, S. E., Jimenez, N., et al. (2007). Diacylglycerol is required for the formation of COPI vesicles in the Golgi-to-ER transport pathway. Mol. Biol. Cell 18, 3250-3263.

Fukuda, M. (2008). Regulation of secretory vesicle traffic by Rab small GTPases. Cell. Mol. Life Sci. 65, 2801-2813.

Garcia-Mata, R., Szul, T., Alvarez, C., and Sztul, E. (2003). ADP-ribosylation factor/COPIdependent events at the endoplasmic reticulum-Golgi interface are regulated by the guanine nucleotide exchange factor GBF1. Mol. Biol. Cell 14, 2250-2261.

Gilchrist, A., Au, C. E., Hiding, J., Bell, A. W., Fernandez-Rodriguez, J., Lesimple, S., et al. (2006). Quantitative proteomics analysis of the secretory pathway. Cell 127 , 1265-1281.

Girod, A., Storrie, B., Simpson, J. C., Johannes, L., Goud, B., Roberts, L. M., et al. (1999). Evidence for a COP-I-independent transport route from the Golgi complex to the endoplasmic reticulum. Nat. Cell Biol. 1, 423-430.

Glick, B. S. (2000). Organization of the Golgi apparatus. Curr. Opin. Cell Biol. 12, 450-456.

Glick, B. S., Elston, T., and Oster, G. (1997). A cisternal maturation mechanism can explain the asymmetry of the Golgi stack. FEBS Lett. $414,177-181$.

Glick, B. S., and Luini, A. (2011). Models for Golgi traffic: a critical assessment. Cold Spring Harb. Perspect. Biol. 3, a005215.

Glick, B. S., and Malhotra, V. (1998). The curious status of the Golgi apparatus. Cell 95, 883-889.

Golgi, C. (1898). Sur la structure des cellules nerveuses. Arch. Ital. Biol. 30, 60-71. 
Gommel, D. U., Memon, A. R., Heiss, A., Lottspeich, F., Pfannstiel, J., Lechner, J., et al. (2001). Recruitment to Golgi membranes of ADPribosylation factor 1 is mediated by the cytoplasmic domain of p23. EMBO J. 20, 6751-6760.

Grasse, P. P. (1957). Ultrastructure, polarity and reproduction of Golgi apparatus. C. R. Hebd. Seances Acad. Sci. 245, 1278-1281.

Griffiths, G. (2000). Gut thoughts on the Golgi complex. Traffic 1, 738-745.

Griffiths, G., Pfeiffer, S., Simons, K., and Matlin, K. (1985). Exit of newly synthesized membrane proteins from the trans cisterna of the Golgi complex to the plasma membrane. J. Cell Biol. 101, 949-964.

Griffiths, G., and Simons, K. (1986). The trans Golgi network: sorting at the exit site of the Golgi complex. Science $234,438-443$.

Gumbiner, B., and Kelly, R. B. (1982). Two distinct intracellular pathways transport secretory and membrane glycoproteins to the surface of pituitary tumor cells. Cell 28, 51-59.

Hauri, H. P., and Schweizer, A. (1992). The endoplasmic reticulum-Golgi intermediate compartment. Curr. Opin. Cell Biol. 4, 600-608.

Heuser, J., and Kirchhausen, T. (1985). Deep-etch views of clathrin assemblies. J. Ultrastruct. Res. 92, 1-27.

Hong, W. (2005). SNAREs and traffic. Biochim. Biophys. Acta 1744, 120-144.

Inoue, H., and Randazzo, P. A. (2007). Arf GAPs and their interacting proteins. Traffic 8, 1465-1475.

Ishizaki, R., Shin, H. W., Mitsuhashi, H., and Nakayama, K. (2008). Redundant roles of BIG2 and BIG1, guanine-nucleotide exchange factors for ADP-ribosylation factors in membrane traffic between the transGolgi network and endosomes. Mol. Biol. Cell 19, 2650-2660.

Jackson, L. P., Lewis, M., Kent, H. M., Edeling, M. A., Evans, P. R., Duden, R., et al. (2012). Molecular basis for recognition of dilysine trafficking motifs by COPI. Dev. Cell 23, 1255-1262.

Jahn, R., and Scheller, R. H. (2006). SNAREs - engines for membrane fusion. Nat. Rev. Mol. Cell Biol. 7, 631-643.

Jensen, D., and Schekman, R. (2011). COPII-mediated vesicle formation at a glance. J. Cell Sci. 124, 1-4.

Jin, L., Pahuja, K. B., Wickliffe, K. E., Gorur, A., Baumgartel, C., Schekman, R., et al. (2012). Ubiquitindependent regulation of COPII coat size and function. Nature 482, 495-500.
Kawamoto, K., Yoshida, Y., Tamaki, H., Torii, S., Shinotsuka, C., Yamashina, S., et al. (2002). GBF1, a guanine nucleotide exchange factor for ADPribosylation factors, is localized to the cis-Golgi and involved in membrane association of the COPI coat. Traffic 3, 483-495.

Keller, P., and Simons, K. (1997). PostGolgi biosynthetic trafficking. J. Cell Sci. 110(Pt 24), 3001-3009.

Kelly, R. B. (1985). Pathways of protein secretion in eukaryotes. Science 230 , 25-32.

Kirchhausen, T., Harrison, S. C., and Heuser, J. (1986). Configuration of clathrin trimers: evidence from electron microscopy. J. Ultrastruct. Mol. Struct. Res. 94, 199-208.

Klumperman, J., Schweizer, A., Clausen, H., Tang, B. L., Hong, W., Oorschot, V., et al. (1998). The recycling pathway of protein ERGIC-53 and dynamics of the ER-Golgi intermediate compartment. J. Cell Sci. 111(Pt 22), 3411-3425.

Ladinsky, M. S., Mastronarde, D. N., McIntosh, J. R., Howell, K. E., and Staehelin, L. A. (1999). Golgi structure in three dimensions: functional insights from the normal rat kidney cell. J. Cell Biol. 144, 1135-1149.

Ladinsky, M. S., Wu, C. C., McIntosh, S., McIntosh, J. R., and Howell, K. E. (2002). Structure of the Golgi and distribution of reporter molecules at 20 degrees $\mathrm{C}$ reveals the complexity of the exit compartments. Mol. Biol. Cell 13, 2810-2825.

Laufman, O., Kedan, A., Hong, W., and Lev, S. (2009). Direct interaction between the COG complex and the SM protein, Sly1, is required for Golgi SNARE pairing. EMBO J. 28, 2006-2017.

Letourneur, F., Gaynor, E. C., Hennecke, S., Demolliere, C., Duden, R., Emr, S. D., et al. (1994). Coatomer is essential for retrieval of dilysinetagged proteins to the endoplasmic reticulum. Cell 79, 1199-1207.

Lippincott-Schwartz, J., Donaldson, J. G., Schweizer, A., Berger, E. G., Hauri, H. P., Yuan, L. C., et al. (1990). Microtubule-dependent retrograde transport of proteins into the ER in the presence of brefeldin A suggests an ER recycling pathway. Cell 60, 821-836.

Liu, S., and Storrie, B. (2012). Are Rab proteins the link between Golgi organization and membrane trafficking? Cell. Mol. Life Sci. 69, 4093-4106.

Losev, E., Reinke, C. A., Jellen, J., Strongin, D. E., Bevis, B. J., and Glick, B. S. (2006). Golgi maturation visualized in living yeast. Nature 441 , 1002-1006.

Lotti, L. V., Torrisi, M. R., Pascale, M. C., and Bonatti, S. (1992). Immunocytochemical analysis of the transfer of vesicular stomatitis virus $\mathrm{G}$ glycoprotein from the intermediate compartment to the Golgi complex. J. Cell Biol. 118, 43-50.

Majoul, I., Straub, M., Hell, S. W., Duden, R., and Soling, H. D. (2001). KDEL-cargo regulates interactions between proteins involved in COPI vesicle traffic: measurements in living cells using FRET. Dev. Cell 1 , 139-153.

Malsam, J., Satoh, A., Pelletier, L., and Warren, G. (2005). Golgin tethers define subpopulations of COPI vesicles. Science 307, 1095-1098.

Malsam, J., and Söllner, T. H. (2011). Organization of SNAREs within the Golgi stack. Cold Spring Harb. Perspect. Biol. 3, a005249.

Mancias, J. D., and Goldberg, J. (2008). Structural basis of cargo membrane protein discrimination by the human COPII coat machinery. EMBO J. 27, 2918-2928.

Marsh, B. J., Mastronarde, D. N., Buttle, K. F., Howell, K. E., and McIntosh, J. R. (2001). Organellar relationships in the Golgi region of the pancreatic beta cell line, HIT-T15, visualized by high resolution electron tomography. Proc. Natl. Acad. Sci. U.S.A. 98, 2399-2406.

Marsh, B. J., Volkmann, N., McIntosh, J. R., and Howell, K. E. (2004). Direct continuities between cisternae at different levels of the Golgi complex in glucose-stimulated mouse islet beta cells. Proc. Natl. Acad. Sci. U.S.A. 101 , 5565-5570.

Martínez-Alonso, E., Ballesta, J., and Martinez-Menarguez, J. A. (2007). Low-temperature-induced Golgi tubules are transient membranes enriched in molecules regulating intra-Golgi transport. Traffic 8 , 359-368.

Martínez-Alonso, E., Egea, G., Ballesta, J., and Martinez-Menarguez, J. A. (2005). Structure and dynamics of the Golgi complex at 15 degrees C: low temperature induces the formation of Golgi-derived tubules. Traffic 6, 32-44.

Martínez-Menárguez, J. A., Geuze, H. J., and Ballesta, J. (1996). Identification of two types of beta-COP vesicles in the Golgi complex of rat spermatids. Eur. J. Cell Biol. 71, 137-143.

Martínez-Menárguez, J. A., Geuze, H. J., Slot, J. W., and Klumperman, J. (1999). Vesicular tubular clusters between the ER and Golgi mediate concentration of soluble secretory proteins by exclusion from COPIcoated vesicles. Cell 98, 81-90.

Martinez-Menárguez, J. A., Prekeris, R., Oorschot, V. M., Scheller, R., Slot, J. W., Geuze, H. J., et al. (2001). PeriGolgi vesicles contain retrograde but not anterograde proteins consistent with the cisternal progression model of intra-Golgi transport. J. Cell Biol. 155, 1213-1224.

Matsuura-Tokita, K., Takeuchi, M., Ichihara, A., Mikuriya, K., and Nakano, A. (2006). Live imaging of yeast Golgi cisternal maturation. Nature 441, 1007-1010.

Melkonian, M., Becker, B., and Becker, D. (1991). Scale formation in algae. J. Electron Microsc. Tech. 17, 165-178.

Miller, V. J., and Ungar, D. (2012). Re'COG'nition at the Golgi. Traffic 13, 891-897.

Mironov, A. A., and Beznoussenko, G. V. (2012). The kiss-and-run Model of intra-Golgi transport. Int. J. Mol. Sci. 13, 6800-6819.

Mironov, A. A., Beznoussenko, G. V., Nicoziani, P., Martella, O., Trucco, A., Kweon, H. S., et al. (2001). Small cargo proteins and large aggregates can traverse the Golgi by a common mechanism without leaving the lumen of cisternae. J. Cell Biol. 155, 1225-1238.

Mironov, A. A., Mironov, A. A. Jr., Beznoussenko, G. V., Trucco, A., Lupetti, P., Smith, J. D., et al. (2003). ER-toGolgi carriers arise through direct en bloc protrusion and multistage maturation of specialized ER exit domains. Dev. Cell 5, 583-594.

Mironov, A. A., Polishchuk, R. S., and Beznoussenko, G. V. (2008). Combined video fluorescence and $3 \mathrm{D}$ electron microscopy. Methods Cell Biol. 88, 83-95.

Moelleken, J., Malsam, J., Betts, M. J., Movafeghi, A., Reckmann, I., Meissner, I., et al. (2007). Differential localization of coatomer complex isoforms within the Golgi apparatus. Proc. Natl. Acad. Sci. U.S.A. 104, 4425-4430.

Mollenhauer, H. H., and Morre, D. J. (1998). The tubular network of the Golgi apparatus. Histochem. Cell Biol. 109, 533-543.

Morvan, J., and Tooze, S. A. (2008). Discovery and progress in our understanding of the regulated secretory pathway in neuroendocrine cells. Histochem. Cell Biol. 129, 243-252.

Nickel, W., Sohn, K., Bunning, C., and Wieland, F. T. (1997). p23, a major COPI-vesicle membrane protein, constitutively cycles through the early secretory pathway. Proc. Natl. Acad. Sci. U.S.A. 94, 11393-11398. 
Nilsson, T., Pypaert, M., Hoe, M. H., Slusarewicz, P., Berger, E. G., and Warren, G. (1993). Overlapping distribution of two glycosyltransferases in the Golgi apparatus of HeLa cells. J. Cell Biol. 120, 5-13.

Oprins, A., Duden, R., Kreis, T. E., Geuze, H. J., and Slot, J. W. (1993). Beta-COP localizes mainly to the cisGolgi side in exocrine pancreas. $J$. Cell Biol. 121, 49-59.

Orci, L., Glick, B. S., and Rothman, J. E. (1986). A new type of coated vesicular carrier that appears not to contain clathrin: its possible role in protein transport within the Golgi stack. Cell 46, 171-184.

Orci, L., Halban, P., Amherdt, M., Ravazzola, M., Vassalli, J. D., and Perrelet, A. (1984). A clathrin-coated, Golgirelated compartment of the insulin secreting cell accumulates proinsulin in the presence of monensin. Cell 39, 39-47.

Orci, L., Perrelet, A., and Rothman, J. E. (1998). Vesicles on strings: morphological evidence for processive transport within the Golgi stack. Proc. Natl. Acad. Sci. U.S.A. 95, 2279-2283.

Orci, L., Ravazzola, M., Volchuk, A., Engel, T., Gmachl, M., Amherdt, M., et al. (2000). Anterograde flow of cargo across the golgi stack potentially mediated via bidirectional "percolating" COPI vesicles. Proc. Natl. Acad. Sci. U.S.A. 97, 10400-10405.

Orci, L., Stamnes, M., Ravazzola, M., Amherdt, M., Perrelet, A., Sollner, T. H., et al. (1997). Bidirectional transport by distinct populations of COPI-coated vesicles. Cell 90, 335-349.

Palade, G. (1975). Intracellular aspects of the process of protein synthesis. Science 189, 347-358.

Patterson, G. H., Hirschberg, K., Polishchuk, S., Gerlich, D., Phair, R. D., and Lippincott-Schwartz, J. (2008). Transport through the Golgi apparatus by rapid partitioning within a two-phase membrane system. Cell 133, 1055-1067.

Pearse, B. M., and Robinson, M. S. (1990). Clathrin, adaptors, and sorting. Annu. Rev. Cell Biol. 6, 151-171.

Pelham, H. R., and Rothman, J. E. (2000). The debate about transport in the Golgi - two sides of the same coin? Cell 102, 713-719.

Polishchuk, R. S., Polishchuk, E. V., Marra, P., Alberti, S., Buccione, R., Luini, A., et al. (2000). Correlative light-electron microscopy reveals the tubular-saccular ultrastructure of carriers operating between Golgi apparatus and plasma membrane. $J$. Cell Biol. 148, 45-58.

Popoff, V., Adolf, F., Brugger, B., and Wieland, F. (2011). COPI budding within the Golgi stack. Cold Spring Harb. Perspect. Biol. 3, a005231.

Presley, J. F., Cole, N. B., Schroer, T. A., Hirschberg, K., Zaal, K. J., and Lippincott-Schwartz, J. (1997). ERto-Golgi transport visualized in living cells. Nature 389, 81-85.

Rabouille, C., Hui, N., Hunte, F., Kieckbusch, R., Berger, E. G., Warren, G., et al. (1995). Mapping the distribution of Golgi enzymes involved in the construction of complex oligosaccharides. J. Cell Sci. 108(Pt 4), 1617-1627.

Rabouille, C., and Klumperman, J. (2005). Opinion: the maturing role of COPI vesicles in intra-Golgi transport. Nat. Rev. Mol. Cell Biol. 6, 812-817.

Rambourg, A., and Clermont, Y. (1997). "Three-dimensional structure of the Golgi apparatus in mammalian cells," in The Golgi Apparatus, eds E. G. Berger and J. Roth (Basel: Birkhauser Verlag), 37-61.

Rambourg, A., Clermont, Y., Chretien, M., and Olivier, L. (1993). Modulation of the Golgi apparatus in stimulated and nonstimulated prolactin cells of female rats. Anat. Rec. 235, 353-362.

Rambourg, A., Clermont, Y., and Hermo, L. (1979). Threedimensional architecture of the golgi apparatus in Sertoli cells of the rat. Am. J. Anat. 154, 455-476.

Rambourg, A., Clermont, Y., and Marraud, A. (1974). Threedimensional structure of the osmium-impregnated Golgi apparatus as seen in the high voltage electron microscope. Am. J. Anat. 140, 27-45.

Roth, J., and Berger, E. G. (1982). Immunocytochemical localization of galactosyltransferase in HeLa cells: codistribution with thiamine pyrophosphatase in trans-Golgi cisternae. J. Cell Biol. 93, 223-229.

Rothman, J. E., and Fine, R. E. (1980). Coated vesicles transport newly synthesized membrane glycoproteins from endoplasmic reticulum to plasma membrane in two successive stages. Proc. Natl. Acad. Sci. U.S.A. 77, 780-784.

Rothman, J. E., and Wieland, F. T. (1996). Protein sorting by transport vesicles. Science 272, 227-234.

Sacher, M., Kim, Y. G., Lavie, A., Oh, B. H., and Segev, N. (2008). The TRAPP complex: insights into its architecture and function. Traffic 9, 2032-2042.
Sadakata, T., Shinoda, Y., Sekine, Y., Saruta, C., Itakura, M., Takahashi, M., et al. (2010). Interaction of calcium-dependent activator protein for secretion 1 (CAPS1) with the class II ADP-ribosylation factor small GTPases is required for densecore vesicle trafficking in the transGolgi network. J. Biol. Chem. 285, 38709-38710.

San Pietro, E., Capestrano, M., Polishchuk, E. V., DiPentima, A., Trucco, A., Zizza, P., et al. (2009). Group IV phospholipase A(2)alpha controls the formation of inter-cisternal continuities involved in intra-Golgi transport. PLoS Biol. 7:e1000194. doi:10.1371/journal.pbio.1000194

Saraste, J., and Kuismanen, E. (1984). Pre- and post-Golgi vacuoles operate in the transport of Semliki Forest virus membrane glycoproteins to the cell surface. Cell 38, 535-549.

Scales, S. J., Pepperkok, R., and Kreis, T. E. (1997). Visualization of ERto-Golgi transport in living cells reveals a sequential mode of action for COPII and COPI. Cell 90, 1137-1148.

Schindler, R., Itin, C., Zerial, M. Lottspeich, F., and Hauri, H. P. (1993). ERGIC-53, a membrane protein of the ER-Golgi intermediate compartment, carries an ER retention motif. Eur. J. Cell Biol. 61, $1-9$.

Schmidt, J. A., Kalkofen, D. N., Donovan, K. W., and Brown, W. J. (2010). A role for phospholipase A2 activity in membrane tubule formation and TGN trafficking. Traffic 11 1530-1536.

Schweizer, A., Fransen, J. A., Matter, K. Kreis, T. E., Ginsel, L., and Hauri, H. P. (1990). Identification of an intermediate compartment involved in protein transport from endoplasmic reticulum to Golgi apparatus. Eur. J. Cell Biol. 53, 185-196.

Semenza, J. C., Hardwick, K. G., Dean, N., and Pelham, H. R. (1990). ERD2, a yeast gene required for the receptor-mediated retrieval of luminal ER proteins from the secretory pathway. Cell 61, 1349-1357.

Sesso, A., de Faria, F. P., Iwamura, E. S., and Correa, H. (1994). A threedimensional reconstruction study of the rough ER-Golgi interface in serial thin sections of the pancreatic acinar cell of the rat. J. Cell Sci. 107(Pt 3), 517-528.

Shiba, Y., and Randazzo, P. A. (2012) ArfGAP1 function in COPI mediated membrane traffic: currently debated models and comparison to other coat-binding ArfGAPs. Histol. Histopathol. 27, 1143-1153.
Shima, D. T., Scales, S. J., Kreis, T. E., and Pepperkok, R. (1999). Segregation of COPI-rich and anterogradecargo-rich domains in endoplasmicreticulum-to-Golgi transport complexes. Curr. Biol. 9, 821-824.

Siddhanta, A., Backer, J. M., and Shields, D. (2000). Inhibition of phosphatidic acid synthesis alters the structure of the Golgi apparatus and inhibits secretion in endocrine cells. J. Biol. Chem. 275, 12023-12031.

Slusarewicz, P., Nilsson, T., Hui, N., Watson, R., and Warren, G. (1994). Isolation of a matrix that binds medial Golgi enzymes. J. Cell Biol. 124, 405-413.

Smith, R. E., and Farquhar, M. G. (1966). Lysosome function in the regulation of the secretory process in cells of the anterior pituitary gland. J. Cell Biol. 31, 319-347.

Stenmark, H. (2009). Rab GTPases as coordinators of vesicle traffic. Nat. Rev. Mol. Cell Biol. 10, 513-525.

Stephens, D. J., Lin-Marq, N., Pagano, A., Pepperkok, R., and Paccaud, J. P. (2000). COPI-coated ER-to-Golgi transport complexes segregate from COPII in close proximity to ER exit sites. J. Cell Sci. 113(Pt 12), 2177-2185.

Storrie, B., White, J., Rottger, S., Stelzer, E. H., Suganuma, T., and Nilsson, T. (1998). Recycling of golgi-resident glycosyltransferases through the ER reveals a novel pathway and provides an explanation for nocodazoleinduced Golgi scattering. J. Cell Biol. 143, 1505-1521.

Strating, J. R., Bouw, G., Hafmans, T. G., and Martens, G. J. (2011). p24 Proteins from the same subfamily are functionally nonredundant. Biochimie 93, 528-532.

Sztul, E., and Lupashin, V. (2009). Role of vesicle tethering factors in the ERGolgi membrane traffic. FEBS Lett. 583, 3770-3783.

Szul, T., and Sztul, E. (2011). COPII and COPI traffic at the ER-Golgi interface. Physiology (Bethesda) 26, 348-364.

Tanaka, K., Mitsushima, A., Fukudome, H., and Kashima, Y. (1986). Three-dimensional architecture of the Golgi complex observed by high resolution scanning electron microscopy. J. Submicrosc. Cytol. 18, 1-9.

Tanigawa, G., Orci, L., Amherdt, M., Ravazzola, M., Helms, J. B., and Rothman, J. E. (1993). Hydrolysis of bound GTP by ARF protein triggers uncoating of Golgi-derived COP-coated vesicles. J. Cell Biol. 123, 1365-1371. 
Taylor, R. S., Jones, S. M., Dahl, R. H., Nordeen, M. H., and Howell, K. E. (1997). Characterization of the Golgi complex cleared of proteins in transit and examination of calcium uptake activities. Mol. Biol. Cell 8, 1911-1931.

Traub, L. M., and Kornfeld, S. (1997). The trans-Golgi network: a late secretory sorting station. Curr. Opin. Cell Biol. 9, 527-533.

Trucco, A., Polishchuk, R. S., Martella, O., Di Pentima, A., Fusella, A., Di Giandomenico, D., et al. (2004). Secretory traffic triggers the formation of tubular continuities across Golgi sub-compartments. Nat. Cell Biol. 6, 1071-1081.

van Rijnsoever, C., Oorschot, V., and Klumperman, J. (2008). Correlative light-electron microscopy (CLEM) combining live-cell imaging and immunolabeling of ultrathin cryosections. Nat. Methods 5, 973-980.

Vázquez-Martínez, R., Díaz-Ruiz, A., Almabouada, F., Rabanal-Ruiz, Y., Gracia-Navarro, F., and Malagon, M. M. (2012). Revisiting the regulated secretory pathway: from frogs to human. Gen. Comp. Endocrinol. 175, 1-9.

Vázquez-Martínez, R., and Malagón, M. M. (2011). Rab proteins and the secretory pathway: the case of rab18 in neuroendocrine cells. Front. Endocrinol. 2:1. doi:10.3389/fendo.2011.00001

Vivero-Salmerón, G., Ballesta, J., and Martínez-Menárguez, J. A. (2008). Heterotypic tubular connections at the endoplasmic reticulum-Golgi complex interface. Histochem. Cell Biol. 130, 709-717.

Volchuk, A., Amherdt, M., Ravazzola, M., Brügger, B., Rivera, V. M., Clackson, T., et al. (2000). Megavesicles implicated in the rapid transport of intracisternal aggregates across the Golgi stack. Cell 102, 335-348.

Volpicelli-Daley, L. A., Li, Y., Zhang, C. J., and Kahn, R. A. (2005). Isoformselective effects of the depletion of ADP-ribosylation factors 1-5 on membrane traffic. Mol. Biol. Cell 16, 4495-4508.

Watanabe, T., Sakai, Y., Koga, D., Bochimoto, H., Hira, Y., Hosaka, M., et al. (2012). A unique ball-shaped Golgi apparatus in the rat pituitary gonadotrope: its functional implications in relation to the arrangement of the microtubule network. J. Histochem. Cytochem. 60, 588-602.

Weidman, P., Roth, R., and Heuser, J. (1993). Golgi membrane dynamics imaged by freeze-etch electron microscopy: views of different membrane coatings involved in tubulation versus vesiculation. Cell 75, 123-133.

Xiang, Y., and Wang, Y. (2011). New components of the Golgi matrix. Cell Tissue Res. 344, 365-379.

Yang, J. S., Gad, H., Lee, S. Y., Mironov, A., Zhang, L., Beznoussenko, G. V., et al. (2008). A role for phosphatidic acid in COPI vesicle fission yields insights into Golgi maintenance. Nat. Cell Biol. 10, 1146-1153.

Yang, J. S., Valente, C., Polishchuk, R. S. Turacchio, G., Layre, E., Moody, D. B., et al. (2011). COPI acts in both vesicular and tubular transport. Nat. Cell Biol. 13, 996-1003.

Yu, S., and Liang, Y. (2012). A trapper keeper for TRAPP, its structures and functions. Cell. Mol. Life Sci. 69 , 3933-3944.

Zeuschner, D., Geerts, W. J., van Donselaar, E., Humbel, B. M., Slot, J. W. Koster, A. J., et al. (2006). Immunoelectron tomography of ER exit sites reveals the existence of free COPIIcoated transport carriers. Nat. Cell Biol. 8, 377-383.

Zhang, Y. C., Zhou, Y., Yang, C. Z., and Xiong, D. S. (2009). A review of ERGIC-53: its structure, functions, regulation and relations with diseases. Histol. Histopathol. 24, 1193-1204.

Conflict of Interest Statement: The authors declare that the research was conducted in the absence of any commercial or financial relationships that could be construed as a potential conflict of interest.

Received: 17 January 2013; accepted: 14 March 2013; published online: 28 March 2013.

Citation: Martínez-Alonso E, Tomás M and Martínez-Menárguez JA (2013) Morpho-functional architecture of the Golgi complex of neuroendocrine cells. Front. Endocrinol. 4:41. doi: 10.3389/fendo.2013.00041

This article was submitted to Frontiers in Neuroendocrine Science, a specialty of Frontiers in Endocrinology.

Copyright (c) 2013 Martínez-Alonso, Tomás and Martínez-Menárguez. This is an open-access article distributed under the terms of the Creative Commons Attribution License, which permits use, distribution and reproduction in other forums, provided the original authors and source are credited and subject to any copyright notices concerning any third-party graphics etc. 